\title{
PENGEMBANGAN ANTENA ARRAY DENGAN STRUKTUR MEBG UNTUK MENGURANGI EFEK MUTUAL COUPLING
}

\author{
Raka Kurnia ${ }^{1}$, Efri Sandi ${ }^{2}$ dan Wisnu Djatmiko ${ }^{3}$ \\ ${ }^{1}$ Mahasiswa Prodi Pendidikan Teknik Elektronika, Fakultas Teknik - UNJ \\ ${ }^{2}$ Dosen Prodi Pendidikan Teknik Elektronika, Fakultas Teknik - UNJ \\ ${ }^{3}$ Dosen Prodi Pendidikan Teknik Elektronika, Fakultas Teknik - UNJ
}

\begin{abstract}
Abstrak. Penelitian ini bertujuan untuk mengurangi efek mutual coupling dari antena array dengan tiga elemen. Peneliti menggunakan tambahan struktur MEBG dengan sampel frekuensi S-band $3 \mathrm{GHz}$. Penelitian dilakukan di Laboraturium Telekomunikasi Fakultas Teknik Universitas Negeri Jakarta pada bulan September 2017 - September 2018. Pengujian terhadap antena mikrostrip dengan tambahan struktur MEBG dilakukan dalam dua tahap, yaitu saat simulasi dan setelah fabrikasi. Terdapat dua antena pada setiap tahapannya yaitu array tanpa penambahan MEBG dan antena array dengan MEBG. Kedua antena dibandingkan sebagai usaha untuk mengukur efektifitas antena. Simulasi menggunakan bantuan software CST Microwave Studio Suite 2014 \&2016 dan antena yang telah difabrikasi diukur dengan bantuan Network Analyzer merk Anritsu S223E. Penambahan struktur MEBG ini berhasil mengurangi nilai mutual coupling sebesar $0,51 \mathrm{~dB}$, dan juga mempengaruhi efek mutual coupling yang berimbas pada naiknya impedansi input sebesar 1,09 $\Omega$. Selain itu dengan struktur MEBG dapat menaikan performansi antena diantaranya berhasil menurunkan nilai return loss, dan membuat antena semakin matching.
\end{abstract}

Kata Kunci: Antena Mikrostrip; Mushroom Electromagnetic Band Gap ( MEBG); Array; Mutual Coupling.

\section{Pendahuluan}

Antena mikrostrip memiliki banyak kelebihan dibandingkan antena lain, namun demikian antena mikrostrip ini juga mempunyai kelemahan yang sangat mendasar, yaitu bandwidth yang sempit, keterbatasan gain dan daya yang rendah [5]. Kelemahan dari antenna bisa diatasi dengan teknik array yaitu dengan menyusun beberapa elemen antena mikrosrip yang identik atau sama percis pada patch. Permasalahan akan kembali muncul ketika elemen dari array jaraknya saling berdekatan, hal itu akan memunculkan efek mutual coupling. Mutual coupling adalah interaksi elektromagnetik yang timbul antara elemen antena pada array [8]. 
Banyak yang menghiraukan efek mutual coupling ini, namun jika array yang digunakan sangat banyak dan jaraknya saling berdekatan efek yang ditimbulkan mutual coupling dapat menurunkan performa antena. Ada beberapa cara yang dapat dilakukan untuk mereduksi efek mutual coupling salah satunya adalah EBG (Electromagnetic Band Gap). Ada banyak beberapa struktur EBG yang dapat digunakan untuk mengurangi efek mutual coupling, struktur mushroom EBG adalah salah satu EBG yang jarang digunakan karena pembuatannya yang rumit yang memerlukan via dielectric patch, sehingga diperlukan struktur mushroom yang lebih simple. Tujuan yang hendak dicapai dalam melakukan penelitian ini adalah mampu mendesain dan menganalisis antena mikrostrip array dengan membandingkan hasil simulasi CST juga membandingkan hasil mengutamakan mengurangi efek mutual coupling di bawah $-20 \mathrm{~dB}$ dengan penambahan struktur MEBG pada frekuensi $3 \mathrm{GHz}$ dengan kriteria uji bandwidth $\pm 50 \mathrm{MHz}$, VSWR di bawah 1,5 dan return loss maksimal $-9,45 \mathrm{~dB}$ serta impedansi input $\pm 50 \mathrm{Ohm}$.

\section{Metode}

\subsection{Desain Antena}

Antena mikrostrip didesain menggunakan software CST 2014 Microwave Studio Suite untuk beroperasi pada frekuensi $3 \mathrm{GHz}$. Desain antena mikrostrip menggunakan bahan FR4 Epoxy untuk dielektrik subtrat dengan ketebalan 1,6 $\mathrm{mm}$. Secara keseluruhan dimensi antena microstrip dihasilkan dari desain optimisasi adalah $76 \mathrm{~mm} \times 76 \mathrm{~mm}$ untuk bahan media dan $23 \mathrm{~mm}$ x 14,5 mm untuk antena patch seperti yang ditunjukkan pada Gambar 1 .

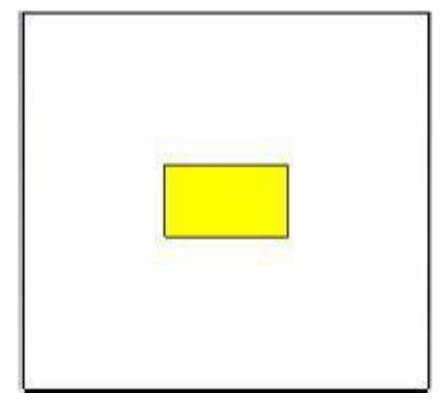

Gambar 1. Antena single element

Untuk mengamati pengaruh struktur MEBG, antena array dirancang dengan 3 elemen seperti yang ditunjukkan pada Gambar. 2. Antena array mikrostrip dirancang menggunakan pencatuan langsung untuk setiap elemen array.

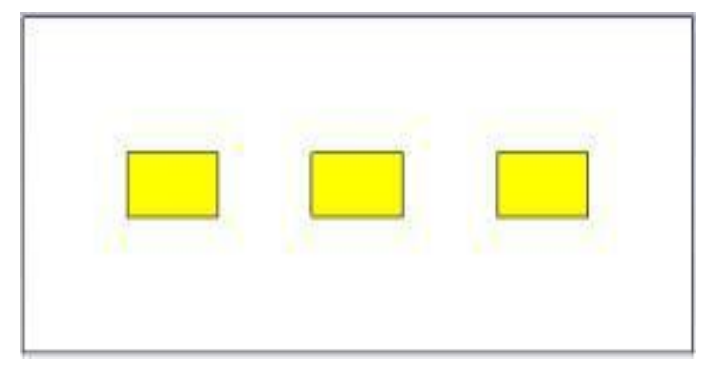

(a) 


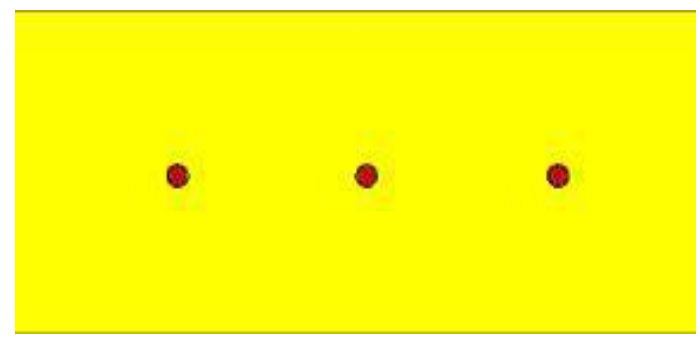

(b)

Gambar 2. Antena array tiga elemen : (a) Tampak Atas (b) Tampak Belakang

\subsection{Desain MEBG}

Desain struktur MEBG dikembangkan berdasarkan empat bagian, bidang tanah, substrat dielektrik, patch logam dan vias penghubung [10]. Prinsip kerja struktur EBG berdasarkan filter LC pada struktur antena array. Nilai LC ini akan mempengaruhi perambatan gelombang permukaan pada struktur antenna mikrostrip [6]. Nilai L dan C yang dapat diekspresikan berdasarkan rumus [7]:

$$
\begin{aligned}
& L=2 * 10^{-7} h\left[\ln \left(\frac{2 h}{r}\right)+0.5\left(\frac{2 r}{h}\right)-0.75\right] \\
& C=\frac{W \varepsilon_{0}\left(1+\varepsilon_{r}\right)}{\pi} \cosh ^{-1}\left(\frac{W+g}{g}\right)
\end{aligned}
$$

0 Adalah permeabilitas ruang bebas, $\mathrm{h}$ adalah ketebalan substrat, $\mathrm{W}$ adalah lebar patch struktur EBG, 0dan g adalah celah antara dua sel MEBG dan izin ruang bebas. Dengan menggunakan nilai $\mathrm{L}$ dan $\mathrm{C}$, frekuensi dari struktur Band gap dapat diprediksi. Dengan menggunakan formula [11], desain MEBG yang dirancang untuk antena miktrostrip $3 \mathrm{GHz}$ ditunjukkan pada Gambar 3. Desain MEBG yang dibuat terdiri dari sel patch MEBG dan celah antara sel MEBG, sedangkan vias penghubung diganti dengan pembuatan lubang atau hole. W sebagai lebar patch adalah sebesar 4,25 $\mathrm{mm}$, g yang merupakan celah antar sel patch adalah sebesar $3,75 \mathrm{~mm}$, dan $\mathrm{r}$ sebagai lubang atau hole adalah sebesar $1,635 \mathrm{~mm}$.

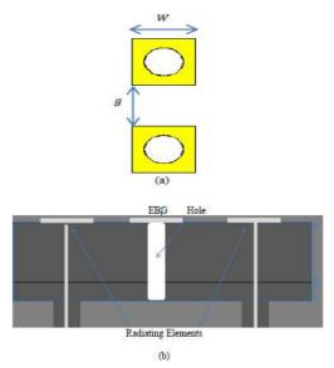

Gambar. 3. Struktur MEBG: (a) Desain sel MEBG; (b) Skematik antena array dan sel MEBG. 


\section{Hasil}

Struktur MEBG ditempatkan di antara elemen patch antena untuk mengurangi efek mutual coupling dari setiap elemen. Sel MEBG ditempatkan di tengah dua patch array elemen dengan jarak $\lambda$ / 8 dari tepi patch seperti yang ditunjukkan pada Gambar 3.

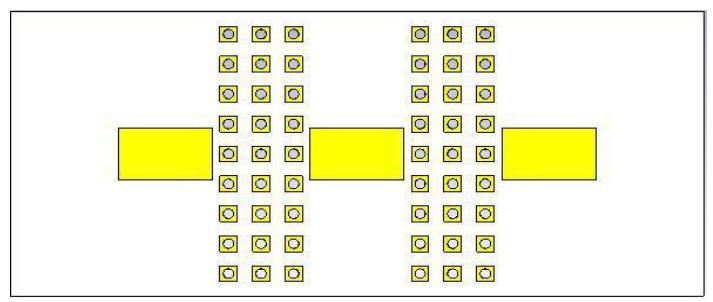

(a)

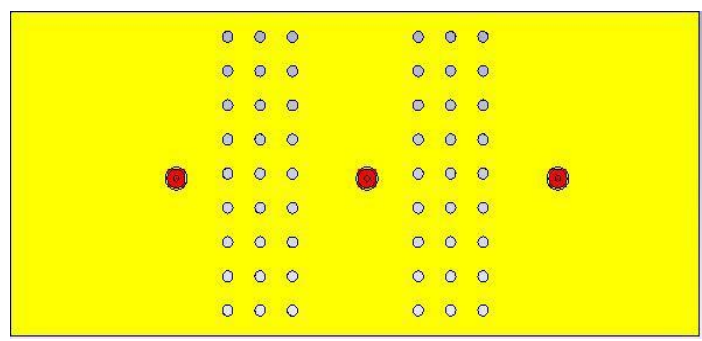

(b)

Gambar 4. Antena dengan struktur MEBG : (a) Tampak Atas; (b) Tampak Bawah

Hasil simulasi antara antena array tanpa struktur MEBG dan antena array dengan struktur MEBG diperlihatkan pada Tabel 1 dan Tabel 2, hasil simulasi meliputi perbandingan parameter umum antena ditunjukkan pada Tabel 1 dan perbandingan mutual coupling ditunjukkan pada Tabel 2. Parameter umum meliputi return loss, VSWR dan bandwidth, sedangkan parameter mutual coupling meliputi nilai mutual coupling itu sendiri dan impedansi input.

Tabel 1. Perbandingan Hasil Simulasi Parameter umum Antena Tanpa MEBG dengan Antena dengan Struktur MEBG

\begin{tabular}{|c|c|c|}
\hline \multirow{2}{*}{ Parameter } & \multicolumn{2}{|c|}{ Simulasi } \\
\cline { 2 - 3 } & Tanpa MEBG & Dengan MBEG \\
\hline S11 & $-17,75 \mathrm{~dB}$ & $-27,84 \mathrm{~dB}$ \\
\hline S22 & $-17,63 \mathrm{~dB}$ & $-28,74 \mathrm{~dB}$ \\
\hline S33 & $-17,90 \mathrm{~dB}$ & $-27,03 \mathrm{~dB}$ \\
\hline VSWR 1 & 1,29 & 1,08 \\
\hline VSWR 2 & 1,30 & 1,07
\end{tabular}




\begin{tabular}{|c|c|c|} 
& & \\
\hline VSWR 3 & 1,29 & 1,09 \\
\hline Bandwidth & $56,1 \mathrm{MHz}$ & $54,6 \mathrm{MHz}$ \\
\hline
\end{tabular}

Tabel 2. Perbandingan Parameter Mutual Coupling antara Antena tanpa MEBG dengan Antena dengan MEBG.

\begin{tabular}{|c|c|c|}
\hline Parameter & \multicolumn{2}{|c|}{ Simulasi } \\
\hline & Tanpa MEBG & Dengan MEBG \\
\hline & & \\
\hline S12 & $-24,64 \mathrm{~dB}$ & $-25,02 \mathrm{~dB}$ \\
\hline & & $-25,02 \mathrm{~dB}$ \\
\hline S21 & $-24,64 \mathrm{~dB}$ & $-32,36 \mathrm{~dB}$ \\
\hline S13 & $-32,15 \mathrm{~dB}$ & $-33,02 \mathrm{~dB}$ \\
\hline & $-32,15 \mathrm{~dB}$ & $-24,61 \mathrm{~dB}$ \\
\hline S31 & & $-24,61 \mathrm{~dB}$ \\
\hline & & \\
\hline S23 & $-24,29 \mathrm{~dB}$ & $33,49 \Omega$ \\
\hline S32 & $-24,29 \mathrm{~dB}$ & \\
\hline & & \\
\hline $\begin{array}{c}\text { Impedansi } \\
\text { Input }\end{array}$ & $31,82 \Omega$ & \\
\hline
\end{tabular}

Antena dengan struktur MEBG dan tanpa MEBG difabrikasi dengan menggunakan jasa pihakketiga diperlihatkan pada Gambar 5.

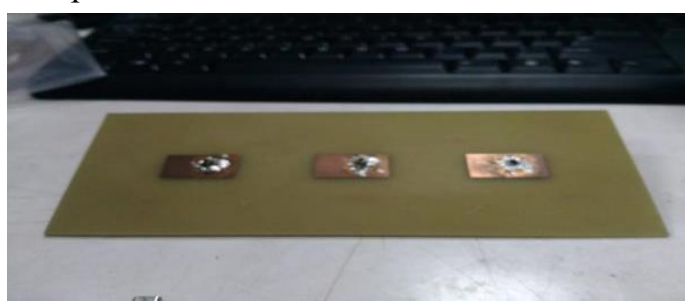

(a)

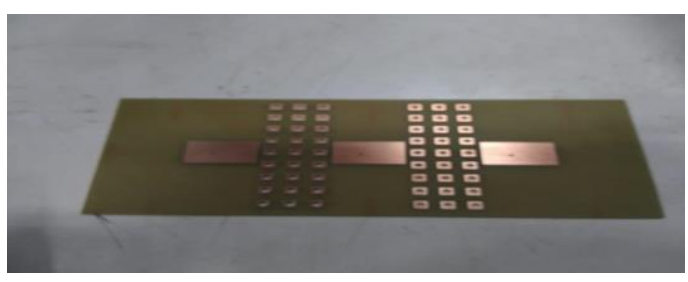

(b)

Gambar 5. Fabrikasi Antena: (a) Array tanpa MEBG; (b) Array dengan MEBG. 
dan dilakukan pengukuran dengan network analyzer. Parameter yang diukur sama dengan parameter yang disimulasikan. Parameter dibandingkan antara antena dengan MEBG dengan tanpa MEBG setelah dilakukan pengukuran. Hasil pengukuran antara antena MEBG dengan antena tanpa MEBG ditunjukkan oleh Tabel 3 dan Tabel 4.

Tabel 3. Perbandingan Hasil Pengujian Antena Parameter Umum Antena dengan MEBG dengan Antena Tanpa MEBG.

\begin{tabular}{|c|c|c|}
\hline Parameter & \multicolumn{2}{|c|}{ Pengukuran } \\
\hline & Tanpa MEBG & Dengan MEBG \\
\hline S11 & $-17,80 \mathrm{~dB}$ & $-27,14 \mathrm{~dB}$ \\
\hline S22 & $-17,51 \mathrm{~dB}$ & $-28,30 \mathrm{~dB}$ \\
\hline S33 & $-17,31 \mathrm{~dB}$ & $-27,14 \mathrm{~dB}$ \\
\hline VSWR 1 & 1,29 & 1,08 \\
\hline VSWR 2 & 1,31 & 1,07 \\
\hline
\end{tabular}

Tabel 4. Perbandingan Hasil Pengujian Antena Parameter Mutual Coupling dengan MEBG dengan Antena Tanpa MEBG.

\begin{tabular}{|c|c|c|}
\hline \multirow{2}{*}{ Parameter } & \multicolumn{2}{|c|}{ Pengukuran } \\
\cline { 2 - 3 } & Tanpa MEBG & Dengan MEBG \\
\hline S12 & $-24,40 \mathrm{~dB}$ & $-24,72 \mathrm{~dB}$ \\
\hline S21 & $-24,40 \mathrm{~dB}$ & $-24,75 \mathrm{~dB}$ \\
\hline S13 & $-24,50 \mathrm{~dB}$ & $-25,40 \mathrm{~dB}$ \\
\hline S31 & $-24,50 \mathrm{~dB}$ & $-25,40 \mathrm{~dB}$ \\
\hline S23 & $-24,40 \mathrm{~dB}$ & $-24,72 \mathrm{~dB}$ \\
\hline S32 & $-24,40 \mathrm{~dB}$ & $-24,72 \mathrm{~dB}$ \\
\hline Impedansi & $44,37 \Omega$ & $45,45 \Omega$ \\
Input & & \\
\hline
\end{tabular}

Meski terdapat perbedaan antara hasil simulasi dan hasil pengukuran, namun kedua hasil menunjukkan sama-sama pengurangan nilai mutual coupling dengan penambahan struktur MEBG. Impedansi input menunjukkan semakin matching atau mendekati $50 \Omega$ dengan penambahan struktur MEBG. Parameter umum antena menunjukkan penaikan performa. 


\section{Kesimpulan}

Penambahan struktur MEBG pada penelitian ini berhasil mengurangi nilai return loss pada tiga elemen yaitu sebesar 7,62 dB untuk return loss elemen pertama, 10,79 dB untuk return loss elemen kedua dan 10,94 dB untuk retutn loss elemen ketiga. Struktur MEBG yang dibuat hanya dengan lubang tanpa menggunakan vias dielectric patch terbukti dapat menurunkan nilai mutual coupling hanya saja nilainya sangat kecil. Namun akan tetap berguna jika digunakan pada antena yang memiliki banyak patch. Apabila nilai mutual coupling menurun, maka berpengaruh pula pada turunnya SLL dan bertambah matchingnya impedansi input. Pada penelitian ini nilai impedansi input bertambah 1,09 $\Omega$. Semakin kecilnya jarak antar sel MEBG (gap) yang diberikan, maka nilai mutual coupling semakin turun, akan tetapi perlu diperhatikan pula geometrinya agar antena tidak memiliki kendala saat proses fabrikasi.

\section{Daftar Pustaka}

1. Y. Rahmat-Samii, "The Marvels of Electromagnetic Band Gap (EBG) Structures," Aces Journal, Vol.18, No.4, November 2003.

2. H. S. Farahani, M. Veysi, M. Kamyab, and A. Tadjalli, "Mutual Coupling Reduction in Patch Arrays Using a UC-EBG Superstrate," IEEE Antennas and Wireless Propagation Letters, Vol.9, 2010.

3. J.-Y. Lee, S.-H. Kim, and J.-H. Jang, "Reduction of Mutual Coupling in Planar Multiple Antenna by Using 1-D EBG and SRR Structures ," IEEE Transaction on Antennas and Propagation Vol. 63, No.9, September 2015.

4. S. Ebadi and A. Semnani, "Mutual Coupling Reduction in Wavegiude-Slot-Array Antennas Using Electromagnetic Bandgap (EBG) Structures," IEEE Antennas and Propagatin Magazine, Vol 56, No.3, June 2014.

5. Surdjati, “Antena Mikrostrip : Konsep dan Aplikasi” Universitas Trisakti, 2014.

6. J. Sandora, "Isolation Improvement with Electromagnetic Band Gap Surfaces," Lincoln Laboratory Journal, Vol.19, No.1, 2012.

7. D. F. Sievenpiper, "High-Impedance Electromagnetic Surface," Ph.D Dissertation, UCLA, 1999.

8. Hon Tat Hui, "Mutual coupling in antenna array." 